\title{
Using mobile technology to conduct epidemiological investigations
}

\author{
Onicio Batista Leal Neto ${ }^{[1]}$, Rodrigo Loyo ${ }^{[1]}$, Jones Albuquerque ${ }^{[2]}$, Juliana Perazzo ${ }^{[3]}$, \\ Verônica Barbosa ${ }^{[1]}$ and Constança Simões Barbosa ${ }^{[1]}$
}

[1]. Laboratório de Esquistossomose, Centro de Pesquisas Aggeu Magalhães, Recife, PE. [2]. Departamento de Informática, Universidade Federal Rural de Pernambuco, Recife, PE. [3]. Núcleo de Estudos de Saúde Coletiva, Centro de Pesquisas Aggeu Magalhães, Recife, PE.

\begin{abstract}
Introduction: The aim of this study was to report the experience of an epidemiological field survey for which data were collected and analyzed using tablets. Methods: The devices used Epi Info 7 (Android version), which has been modeled a database with variables of the traditional form. Results: Twenty-one households were randomly selected in the study area; 75 residents were registered and completed household interviews with socioeconomic and environmental risk variables. Conclusions: This new technology is a valuable tool for collecting and analyzing data from the field, with advantageous benefits to epidemiological surveys.
\end{abstract}

Keywords: Schistosomiasis. Epidemiology. Mobile. Android. Epi 7.

To ensure efficiency, agility, and accuracy, it is essential that public health services are instrumented with basic epidemiological information generated by new technological tools. With the global trend of generating technologies in various sectors, public health tools can incorporate dynamic information, which can also be accessible to the individual user/ health systems ${ }^{(1)}$. These new technologies promote the collection of information in a short time, thus enabling quick thinking in cases of necessary intervention strategies ${ }^{(2)}$. This new array of technologies may be applied to mobile systems, particularly smartphones $^{(3)}$, with features such as remote web access, a Global Positioning System (GPS) signal, huge data storage, and a text editor. Morris ${ }^{(4)}$ demonstrated a few applications that could be used on mobile phones for the collection of public health information. The use of these devices has as great advantage, enabling direct contact between the health authorities and users and allowing participants to feel more involved in territorial health/diseases processes. Ardanza ${ }^{(2)}$ presented other experiences with mobile phone use; in particular, this instrument was used to promote health information in remote areas of African countries.

Modern smartphones with Android (operating system developed by Google), iOS (operating system developed by Apple), and Windows Mobile operating platforms may be

\footnotetext{
Address to: Dr. Onicio Batista Leal Neto. Av. Professor Moraes Rego s/n, Cidade Universitária, 50740-465 Recife, PE, Brasil.

Phone: 5581 2101-2572

e-mail: onicio@gmail.come-mail; onicio@gmail.com

Received 14 August 2014

Accepted 19 November 2014
}

implemented in epidemiological field studies, particularly since GPS integration allows for spatial data to be included in the registration interfaces. In addition, data transcription errors are minimized, and there is remote and real-time communication between the information collected in the field and an online storage $^{(3)(5)(6)(7)(8)}$.

In August 2012, the Centers for Disease Control and Prevention released a new version of Epi Info software for epidemiological studies, with support for mobile platforms (smart phones and tablets) using the Android operating system. This version allows for those with no programming skills to develop their own forms to collect data on tablets, thereby providing improved processes related to this activity.

The aim of this paper is to report the experience of an epidemiological field survey for which socioeconomic and environmental data were collected and analyzed using tablets with the Epi Info 7 mobile platform, with remote transmission of information in real time.

This partial, exploratory, cross-sectional test was part of a larger survey being conducted by the Schistosomiasis Lab and Reference Service (Aggeu Magalhães Research Center/ FIOCRUZ) located in Praia do Forte Orange, Itamaracá, Pernambuco, where there is a record of schistosomiasis transmission spanning more than 20 years ${ }^{(9)(10)(11)(12)}$.

To use Epi Info 7 to collect data on Android tablets, it was necessary to download the application via the website (http://epiinfoandroid.codeplex.com/) to ensure compatibility with OS version 4.0 or higher. The main features of the application are: 1) data collection in a structured form;2) capture of coordinate pairs for georeferencing of data collection; 3) data export format of comma separated values (CSV); 4) cloud synchronization with data visualization arranged in dashboards; 
and 5) statistical calculator for epidemiologists. The Epi 7 Android app is hosted in a virtual repository, and the download source is unofficial (not been Play Store). For correct installation, allow downloads from unknown sources was enabled in the settings menu of the Android device. The forms were constructed in the desktop environment of Epi Info (Figure 1) and exported via USB connection to the tablets (Figure 1). The variables were transformed into a bank for entry programming and data analysis; this allowed for the production of lists, frequency distributions, statistical analysis, graphs, and maps. In the present study, $\chi^{2}$ hypothesis testing was performed to estimate the value of the variable dispersion assessing the association between variables.

To enable the remote transmission of information in real time, chips data connection via $3 \mathrm{G}$ was acquired.

To test the mobile technology in question, 21 households were randomly selected in the study area; 75 residents were registered and completed household interviews with socioeconomic and environmental risk variables. The traditional method of collecting and recording data in field surveys (use of clipboards, paper forms, pencil/pen, etc.) was entirely replaced by GPS devices and cameras.

New technologies may be used as tools for collecting and analyzing data from the field, with advantageous benefits to epidemiological investigations. This promotes the accurate and efficient collection of data and is a safe, practical, and fast way to transmit the information in real time, allowing for instant visualization of scenarios in exploratory studies. For the transmission of data in real time and synchronization, it was necessary to hire two services: 1) a data plan where a chip is necessary to connect via $3 \mathrm{G}$; and 2) a storage and data management service in the cloud service Microsoft Azure. The cost of hiring data service plans may be replaced if there is a Wi-Fi connection when field teams return to base, or by installing hotspots in vehicles at the field. With regard to the costs of hiring the Azure cloud service, there is a possibility that the gratuity limit space does not exceed $1 \mathrm{~GB}$ of storage. In it there are possibilities are configured table where the real-time query can be made by viewing the data in that field are filled.

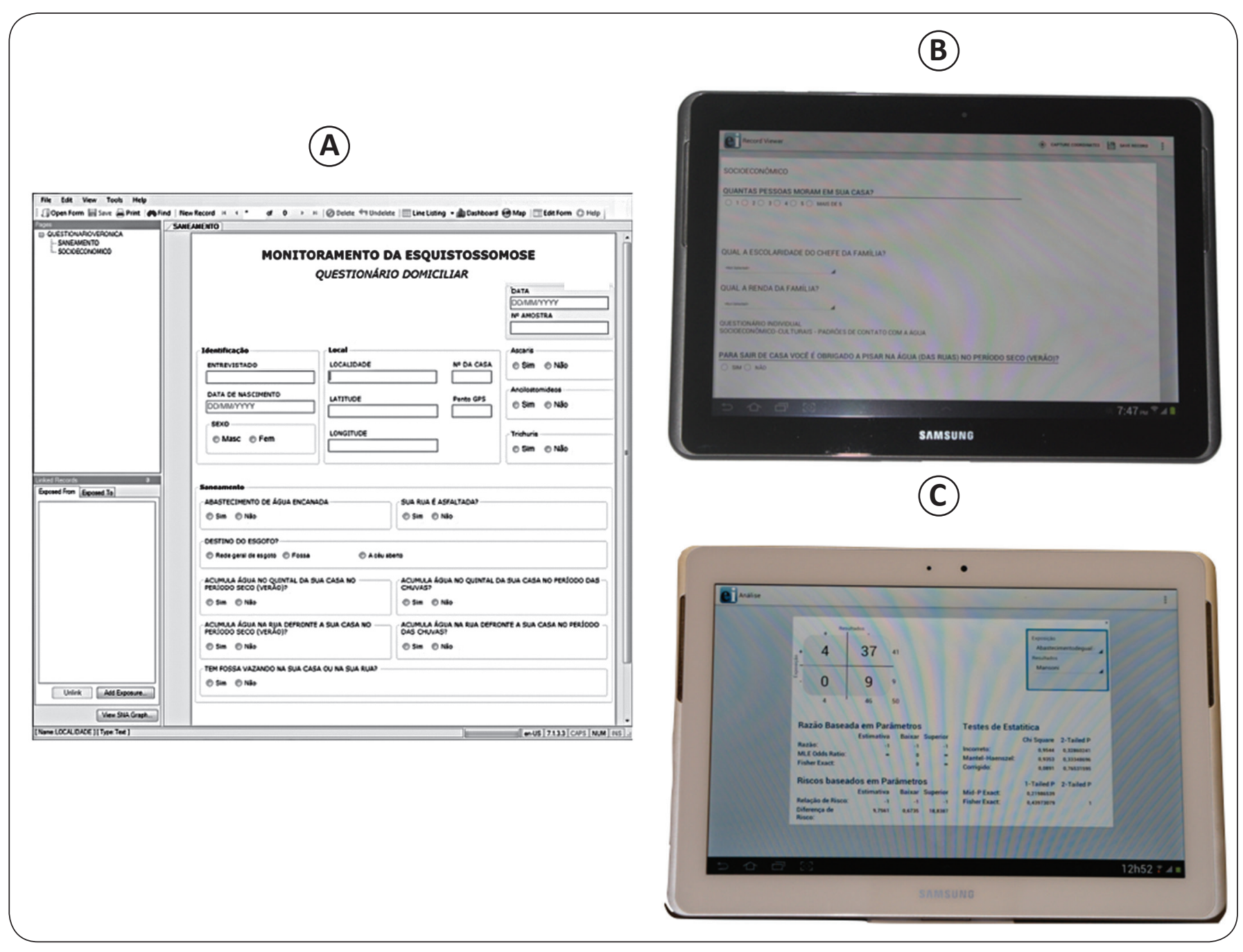

FIGURE 1 - Epi Info questionnaire on the desktop (A) and tablet (B). Epi Info data analysis (C). 
The Figure 1 shows the Epi Info questionnaire as seen on the desktop (A) and tablet, both for data collection (B) and analysis (C). The data were entered and simultaneously sent to computer files at CPqAM/FIOCRUZ, which was the coordinated base of this project. This feature of real-time transmission allowed for remote and instant communication between field technicians; this facilitated project coordination and the exchange of information and preliminary analyses, and also allowed for the recasting of collection strategies as necessary.

During the implementation of the household questionnaire, the respondents were familiar with the terms tablet, internet, and technology. This fact, although not quantified, indicates how these trends already cover various social classes, demonstrating the technological spread among populations.

The main goal of the study was to establish the performance of collecting data via tablets with Epi Info 7. The results indicated that this method improved safety, speed, and convenience in data collection, showing that this type of instrument can be used in both routine health (surveillance and healthcare) services and the academic research. Epi Info 7 is free, and anyone with basic knowledge of the platform can create quizzes to apply them to their studies. The export of questionnaires to tablets or smartphones is also convenient, requiring only a USB connection between the device and the computer on which the form was created. Forms may also be transmitted by e-mail, through an XML file that can be easily created within Epi Info 7, thus facilitating the distribution of data in multicenter studies. The difference between the use of tablets and smartphones will depend only on users, since the costs are currently compatible, with no significant differences.

The major limitations of the strategy are based on the risk of equipment theft in low-income regions. Another limitation, although rare, is that the system may crash in some situations because of data overload on the tablets. However, due to redundancy storage (cloud and native database device), information security may still be ensured.

The study is still being developed and preliminary results indicate the importance of using new tools that promote developments in data collection, with substantial gains in technical, financial, and informational view.

\section{CONFLICT OF INTEREST}

The authors declare that there is no conflict of interest.

\section{REFERENCES}

1. Bulkley K. Mobile phones bring revolution to developing world: A wave of mobile technology spreading across the third world promises more efficient disaster relief, cheaper energy and a faster route out of poverty. The Guardian [Internet]. [Cited 2013 Jul 25]. Available at: http://technews.tmcnet.com/business-video/ news/2010/01/22/4586351.htm

2. Ardanza N. Physician uses cell phones to bring health care to the poor Voice of America [Internet]. [Cieted 2013 Jul 25]. Available at: http:/ /www.voanews.com/content/physician-uses-cell-phones-to-bringhealth-care-to-the-poor-82403437/162815.html/.

3. Freifeld CC, Chunara R, Mekaru SR, Chan EH, Kass-Hout T, Ayala Iacucci A, et al. Participatory epidemiology: Use of mobile phones for community-based health reporting. PLoS Med 2010; 7 : e1000376.

4. Morris RR. Managing sound sensitivity in autism spectrum disorder: New technologies for customized intervention, Master's thesis. Massachusetts (EUA): Massachusetts Institute of Technology; 2009. [Cited 2014 March 05]. Available at: http://affect.media.mit. edu/pdfs/09.Morris-thesis.pdf

5. Aanensen DM, Huntley DM, Feil EJ, al-Own F, Spratt BG. EpiCollect: Linking smartphones to web applications for epidemiology, ecology and community data collection. PLoS One 2009; 4: e6968.

6. Zolfo M, Iglesias D, Kiyan C, Echevarria J, Fucay L, Llacsahuanga $\mathrm{E}$, et al. Mobile learning for HIV/AIDS healthcare worker training in resource-limited settings. AIDS Res Ther 2010; 7:35.

7. Boulos MN, Wheeler S, Tavares C, Jones R. How smartphones are changing the face of mobile and participatory healthcare: An overview, with example from eCAALYX. Biomed Eng Online 2011; 10:24.

8. Leal-Neto OB, Albuquerque J, Souza EC, Barbosa CS. Estrategias do Futuro para enfrentar problemas do passado. Scientific Amer Brasil 2011; 106: 48-51.

9. Barbosa CS, Barbosa FS. Padrão epidemiológico da esquistossomose em comunidade de pequenos produtores rurais de Pernambuco, Brasil. Cad Saude Publica 1998; 14:129-138.

10. Barbosa CS, Pieri O, Barbosa FS. Ecoepidemiologia da Esquistossomose urbana na Ilha de Itamaracá. Rev Saude Publica; 2000; 34: 337-341.

11. Barbosa CS, Araujo K, Favre TC, Pieri O. Spatial distribution of schistosomiasis foci on Itamaracá Island, Pernambuco, Brazil. Mem Inst Oswaldo Cruz 2004; 99:79-83.

12. Barbosa CS, Araújo KC, Sevilha MA, Melo F, Gomes ECS, SouzaSantos R. Current epidemiological status of schistosomiasis in the state of Pernambuco, Brazil. Mem Inst Oswaldo Cruz 2010; 105:549-554. 